\title{
Craniosynostosis-dental anomalies
}

INSERM

\section{Source}

INSERM. (1999). Orphanet: an online rare disease and orphan drug data base.

Craniosynostosis-dental anomalies. ORPHA:284149

Craniosynostosis-dental anomalies is a rare, genetic, cranial malformation syndrome characterized by premature fusion of multiple or all calvarial sutures (resulting in variable abnormal shape of the head), midface hypoplasia, delayed and ectopic tooth eruption and supernumerary teeth. Associated facial dysmorphism includes proptosis, hypertelorism, beaked nose, and relative prognathism. Variable digital anomalies (e.g. finger and/or toe syndactyly, clinodactyly), short stature, cognitive and/or motor delay, high palate, ear deformity and conductive hearing loss have also been reported. 